\title{
Economic Impact of Violence Against Women in Senegal: Estimation of Costs of Productivity Losses
}

\author{
Mamadou Makhtar Mbacké Leye, Ibrahima Seck, Anta Tal Dia \\ Department Preventive Medicine and Public Health, Faculty of Medicine, Pharmacy and Odontology, University Cheikh Anta Diop, Dakar, \\ Senegal
}

Email address:

mamadou.leye@yahoo.fr (M. M. M. Leye)

\section{To cite this article:}

Mamadou Makhtar Mbacké Leye, Ibrahima Seck, Anta Tal Dia. Economic Impact of Violence Against Women in Senegal: Estimation of Costs of Productivity Losses. World Journal of Public Health. Vol. 5, No. 2, 2020, pp. 30-36. doi: 10.11648/j.wjph.20200502.11

Received: February 21, 2020; Accepted: March 25, 2020; Published: April 14, 2020

\begin{abstract}
The objective of this study was to analyse the costs of productivity losses of violence against women in Senegal. The costs of lost productivity were calculated from the database derived from the epidemiological survey at the level of Senegal's courts. The basis of the epidemiological survey allowed the information to calculate the costs. These costs include lost pay and time for those considered to be victims, but also for perpetrators. The human capital approach was used. The total costs of productivity losses were estimated 105,792 € for the victims and 2,926,543€ for the perpetrators. The costs of lost productivity of the perpetrators who committed sexual violence were estimated $1,868,499 €$ or $64 \%$ of the total costs. The costs related to productivity losses for both victims and perpetrators in regards to murders and rapes accounted for the following percentage of the total costs $49.6 \%$ and $52.6 \%$, respectively. Depending on the types of sectors and violence, the average costs of productivity losses were statistically higher among the perpetrators compared to the victims $(p<0.05)$. This study highlights the high costs of violence borne by society. An analysis of direct costs would have provided a better understanding of the economic burden of this violence.
\end{abstract}

Keywords: Prevention, Cost, Productivity, Violence, Woman, SENEGAL

\section{Introduction}

Violence against women produces negative effects on women's health. They negatively impact their physical integrity with bodily injury, and cause disturbances that are psychological, gynaecological obstetrics and economic. According to the World Health Organization, violence damages lives and its economic cost weighs heavily on societies around the world; some of which spend more than $4 \%$ of their gross domestic product addressing the traumas of violence [20]. The costs of lost productivity are indirect costs defined as lost profits. These losses arise out of the impossibility or reduction in productivity attributable to violence; through the disabilities, diseases, and mortality caused by this violence. The significant costs of production losses in relation to the overall cost of violence are comparable to those found in cost studies of chronic diseases. In the United States, the total annual expenditure associated with depression can be estimated at 100 billion euros ( 83 billion USD in 2000), 69\% of which accounts for job losses and premature deaths $[7,30]$. In Africa, in the Democratic Republic of Congo, women are in the crossfires of the conflict economy as they are victims of the terror of rape as a weapon of war and are victims of submission [6]. Currently, Senegal does not have national data on violence. A review of the literature provides information on partial data. Not a day goes by without the press reporting at least one case of physical and/or sexual violence [15]. The situational analysis of violence against women is of great importance in the implementation of effective strategies to combat such violence. Likewise, there have been no scientific studies conducted in Senegal to evaluate the costs of violence.

The harms of violence against women are deep and lasting. While direct damages on the victim's physical and mental health are the most obvious signs, domestic violence also has a significant impact on victim's ability to work and their productivity [13]. The objective of this study is to analyse the costs of productivity losses of violence against women in Senegal. 


\section{Framework of Study}

Senegal, or the Republic of Senegal, is a country in West Africa. It is bordered by the Atlantic Ocean to the west, Mauritania to the north, Mali to the east, and Guinea and Guinea-Bissau to the south. This study was conducted on all Regional High Courts (RHC) in Senegal. The RHC is a first degree civil court which is concerned with some of the disputes between private individuals (individuals, associations, etc.).

\section{Methods}

The costs of lost productivity were calculated from the database derived from the epidemiological survey conducted through the RHC of Senegal. The study period ran from October 09, 2015 to October 15, 2017. The study population consisted of the court files of girls or women who were victims of physical and / or sexual violence registered at the high court level during the period from 2006 to 2015.

Violence leads to indirect costs in the form of lost productivity.

Violence leads to indirect costs in the form of lost productivity. These costs include lost pay and time for those considered to be victims (work stoppages, loss of human capital related to premature deaths), but also for perpetrators (incarcerations).

It should be noted that the human capital approach was used. This approach consists of multiplying the number of hours of work lost due to illness by the gross salary, and adding the employer's social security contributions [5]. According to
Drummond M. F et al, the goal is to multiply the number of hours lost due to illness by the average hourly wage. First and foremost, we used this approach to estimate the total time lost for morbidity and mortality on the basis of an average wage [5]. The productivity losses generated by work stoppages were calculated from the number of days of absence in the database resulting from the epidemiological survey.

The productivity losses incurred by premature deaths are, for their part, estimated over the period starting from the concerned age up to the theoretical age of retirement (60 years) [24]. The cost of lost productivity (CLP) is determined by the number of workdays lost for each victim and perpetrator. The number of days of total incapacity for work for victims and the length of imprisonment for perpetrators were taken into account. We will consider all victims who are under 60 years of age, retirement age [16]. The basis of the epidemiological survey allowed for the individualization of the professions of victims and perpetrators and the information concerning the duration of victims' temporary incapacity for work (TIW) and the perpetrator's duration of imprisonment. Thus, as in the employment survey of the National Agency for Statistics and Demography, workers amongst victims and perpetrators were classified in the following sectors [4]:

1. Public $=$ executives, employees, labourers, and others

2. Formal private $=$ managers, employees, labourers, and others

3. Informal private $=$ self-employed workers, employees, labourers and others

It consists of multiplying the number of working days lost due to violence by the average daily wage of each occupational category $[12,18]$ (table 1$)$.

Table 1. Average monthly ages of workers in different sectors from 2006 to 2015 in Senegal.

\begin{tabular}{ll}
\hline Sector & Average monthly salary \\
\hline Public & $203 €$ \\
Formal private & $323 €$ \\
Informal private & $64 €$ \\
\hline
\end{tabular}

1 euro $=655.957$ FCFA (Franc Financial Community in Africa).

\subsection{Descriptive Cost Study}

\subsubsection{Costs of Lost Productivity (Clp) Related to Temporary Incapacity for Work}

CLP public sector victim $=\Sigma$ (average daily salary public sector * number of days of total incapacity for work victim public sector)

CLP victim formal private sector $=\Sigma$ (average daily wage formal private sector $*$ number of days of total incapacity for work victim private formal sector)

CLP victim informal private sector $=\Sigma$ (average daily wage informal private sector * number of days of total incapacity for work victim informal private sector)

CLP total victim $=$ CLP victim public sector + CLP victim private sector formal + CLP victim private sector informal

\subsubsection{Cost of Lost Productivity Related to Incarceration}

CLP public sector perpetrator $=\Sigma$ (average daily public sector wage * duration in days of incarceration for perpetrator public sector)

CLP aggressor formal private sector $=\Sigma$ (average daily wage formal private sector * duration in days of incarceration for perpetrator formal private sector)

CLP aggressor informal private sector $=\Sigma$ (average daily wage informal private sector $*$ duration in days of incarceration for perpetrator private sector informal)

CLP total aggressor=CLP perpetrator public sector + CLP formal perpetrator private sector + CLP perpetrator informal private sector 


\subsubsection{Loss of Productivity Costs Related to Mortality (Lpcm)}

On the basis of the age of retirement, the cost of lost productivity was determined by the number of years lost to death.

We will consider all offenders who are under 60 years of age (retirement age). Number of days lost $=(60$-deceased age $) * 12 * 20$.

LPCM public sector victim $=\Sigma$ (average daily salary public sector * number of days lost victim public private sector)

$\mathrm{LPCM}$ victim formal private sector $=\Sigma$ (average daily wage formal private sector * number of days lost victim formal private sector)

LPCM victim informal private sector $=\Sigma$ (average daily wage informal private sector $*$ number of days lost victim informal private sector)

LPCM total victim=LPCM victim public sector + LPCM victim formal private sector + LPCM victim informal private sector

\subsubsection{Total Costs of Lost Productivity Due to Violence (Tclp)}

$\mathrm{TCLP}=\mathrm{CLP}$ total victim + CLP total perpetrator + LPCM total victim

\subsection{Cost Analysis Study}

A comparison of the cost averages for perpetrators and victims was conducted by industry, type of violence and form of violence. The Student's test was used and was significant when the p-value was less than 0.05 .

\section{Ethical Considerations}

The data are collected anonymously and kept confidential. Only study managers have access to the database. No information can be published without their agreement.

\section{Results}

\subsection{Descriptive Results}

At the end of the recruitment, 2755 cases of victims of physical and / or sexual violence were enlisted.

\subsubsection{Sociodemographic Characteristics}

The average age of victims and perpetrators were $23.3 \pm$ (14.2) years and $31.3 \pm(11.8)$ years respectively. The male sex was predominant among the perpetrators, accounting for $86.9 \%$. Among the victims, $37 \%$ were educated. Informal private sector victims and perpetrators predominated respectively in 59\% and $89 \%$ (Table 2).

Table 2. Sociodemographic characteristics of victims and perpetrators from 2006 to 2015 in Senegal.

\begin{tabular}{lll}
\hline Characteristics & Victims & Perpetrators \\
\hline $\begin{array}{l}\text { Average age } \pm \text { Standard } \\
\text { deviation }\end{array}$ & $23.3 \pm(14.2)$ years & $31.3 \pm(11.8)$ years \\
$\begin{array}{l}\text { Minimum-Maximum } \\
\text { Sex }\end{array}$ & 4 months-83 years & 12 years-106 years \\
Male & $0 \%$ & \\
Female & $100 \%$ & $86.9 \%$ \\
Educated & & $13.1 \%$ \\
Yes & $37 \%$ & \\
No & $63 \%$ & $30.5 \%$ \\
Sector of activities & & $69.5 \%$ \\
Public & $8 \%$ & $6 \%$ \\
Formal private & $33 \%$ & $5 \%$ \\
Informal private & $59 \%$ & $89 \%$ \\
\hline
\end{tabular}

\subsubsection{Productivity Loss Costs by Sector of Activity}

The total cost of productivity losses for the victims was estimated at $105,729 €$.

These lost costs were higher in the informal sector, which represents $62 \%$ of the total costs. The total cost of productivity losses for the perpetrators was estimated at $2,926,543 €$. These lost costs were higher in the informal sector, accounting for $67 \%$ of total costs (Table 3 ).

Table 3. Costs of lost productivity of victims by sector from 2006 to 2015 in Senegal.

\begin{tabular}{lll}
\hline Sectors & Costs of lost productivity $(\boldsymbol{€})$ & Percent $(\%)$ \\
\hline Victims & & \\
Public & 4,714 & 4 \\
Formal private & 35,799 & 34 \\
Informal private & 65,217 & 62 \\
Total & 105,729 & 100 \\
Perpetrators & & \\
Public & 503,119 & 17.2 \\
Formal private & 480,263 & 16.4 \\
Informal private & $1.943,161$ & 66.4 \\
Total & $2,926,543$ & 100 \\
\hline
\end{tabular}

1 euro $=655.957$ FCFA.

\subsubsection{Productivity Loss Costs by Types of Violence}

The costs of productivity losses for victims of physical violence were estimated at $96,769 €$ which represents $92 \%$ of total costs. The costs of productivity losses for perpetrators of sexual violence were estimated at $1,868,499 €$ which represents $64 \%$ of the total costs (Table 4 ).

Table 4. Costs of productivity loss by types of violence from 2006 to 2015 in Senegal.

\begin{tabular}{lll}
\hline Types of violence & Costs of lost productivity $(\boldsymbol{€})$ & Percentage $(\%)$ \\
\hline Victims & & \\
Physical & 96,769 & 92 \\
Physical and sexual & 5,629 & 5 \\
Sexual & 3,331 & 3 \\
Total & 105,729 & 100 \\
Perpetrators & & \\
Physical & 350,822 & 12 \\
Physical and sexual & 707,222 & 24.2 \\
Sexual & $1,868,499$ & 63.8 \\
Total & $2,926,543$ & 100 \\
\hline
\end{tabular}

1 euro $=655.957$ FCFA. 


\subsubsection{Costs of Productivity Losses in Regards to the Forms of Violence}

Costs related to productivity losses among victims arose mainly out of murders $(€ 52,434)$ and intentional injuries $(€ 43,688)$ representing $50 \%$ and $41 \%$ of the total costs respectively.

Costs related to productivity losses amongst perpetrators were mainly related to rape $(€ 1,546,389)$ and intentional injuries + rape $(€ 561,261)$ accounting for $53 \%$ and $19 \%$ of the total costs respectively (Table 5).

Table 5. Costs of productivity loss by form of violence from 2006 to 2015 in Senegal.

\begin{tabular}{|c|c|c|}
\hline Forms of violence & Cost of lost productivity (€) & Percentage (\%) \\
\hline \multicolumn{3}{|l|}{ Victims } \\
\hline Murders & 52,434 & 49.6 \\
\hline Intentional injuries & 43,688 & 41.3 \\
\hline Other sexual violence + intentional injuries & 2,828 & 2.7 \\
\hline Rapes + intentional injuries & 2,802 & 2.7 \\
\hline Rapes & 1,924 & 1.8 \\
\hline Other sexual violence & 1,407 & 1.4 \\
\hline Total & 105,729 & 100 \\
\hline \multicolumn{3}{|l|}{ Perpetrators } \\
\hline Rapes & $1,546,389$ & 52.8 \\
\hline Intentional injuries + rapes & 561,261 & 19.2 \\
\hline Intentional injuries + murders & 350,694 & 12 \\
\hline Other sexual violence & 314,527 & 10.8 \\
\hline Intentional injuries + other sexual violence & 150,266 & 5.1 \\
\hline Total & $2,923,494$ & 100 \\
\hline
\end{tabular}

1 euro $=655.957$ FCFA.

\subsection{Analytical Results: Comparison of Average Costs for Victims and Perpetrators}

Depending on the types of sectors and violence, the average costs of productivity losses were statistically higher among the perpetrators compared to the victims $(\mathrm{p}<0.05)$ (Table 6).

Table 6. Comparison of average costs of productivity $(€)$ losses among victims and perpetrators from 2006 to 2015 in Senegal.

\begin{tabular}{|c|c|c|c|c|c|c|}
\hline & & \multicolumn{2}{|l|}{ Victims } & \multicolumn{2}{|c|}{ Perpetrators } & \multirow{2}{*}{$\mathbf{P}$} \\
\hline & & Number & Mean (SD) & Number & Mean (SD) & \\
\hline \multirow{3}{*}{$\begin{array}{l}\text { Sector of } \\
\text { activities }\end{array}$} & Public & 33 & $143(48)$ & 71 & $7086(9016)$ & $<0.0001$ \\
\hline & Formal private & 137 & $261(109)$ & 56 & $8576(12436)$ & 0.00006 \\
\hline & Informal private & 247 & $52(26)$ & 1009 & $1926(2484)$ & $<0.0001$ \\
\hline \multirow{3}{*}{$\begin{array}{l}\text { Types of } \\
\text { violence }\end{array}$} & Physical & 302 & $147(123)$ & 373 & 941 (2779) & $<0.0001$ \\
\hline & Physical and Sexual & 46 & $122(99)$ & 228 & $3102(5359)$ & 0.0002 \\
\hline & Sexual & 69 & $48(51)$ & 535 & $3493(5010)$ & $<0.0001$ \\
\hline \multirow{4}{*}{$\begin{array}{l}\text { Forms of } \\
\text { violence }\end{array}$} & Rapes & 49 & $39(37)$ & 361 & $4284(5424)$ & $<0.0001$ \\
\hline & Other sexual violence & 20 & $70(37)$ & 174 & $1808(3470)$ & 0.026 \\
\hline & Other sexual violence + intentional injuries & 23 & $123(99)$ & 108 & $1391(2869)$ & 0.036 \\
\hline & Rape + intentional injuries + Violence and assault & 102 & $74(83)$ & 714 & $3453(5181)$ & 0.0001 \\
\hline
\end{tabular}

SD: Standard deviation 1 euro $=655.957$ FCFA.

\section{Discussion}

The human capital approach measures potential lost productivity, rather than the actual loss incurred by society. The estimation of the cost of lost productivity related to violence against women and girls in our study is based mainly on existing data collected at the level of Senegal's high courts. This data, despite constituting a necessary starting point, remain very insufficient because they are incomplete which limit our ability to evaluate the extent of the economic weight of these abuses. By exploiting existing data, this cost study nonetheless faces methodological problems related to time limits. One limitation is the selection of a restricted time horizon in the evaluation of a time-spread phenomenon [19].
Ideally, the impact of violence against women and girls on the community should be measured throughout the life of the victim and his / her family, and not be limited by a restricted time period and lacking judicial files of the victims. In addition, the duration of temporary incapacity for work (TIW) used in our study to measure the costs of lost productivity is an estimate. The actual duration of TIW is determined by the work stoppage or by the temporary incapacity for work (defined by the impossibility to work because of his state of health targeting the employees) but this information is not available in the victim's file. The duration of TIW was also used among victims of rape because the latter presented mental or psychological disorders such as post-traumatic stress disorder. In these cases, these TIWs should be determined by 
specialists in those areas as recommended by Huck A et al [11]. For the perpetrators, the present estimate values productivity losses due to time spent in prison without taking into account the consequences of unemployment for people leaving prison.

Another limitation of the study Productivity losses were not adjusted for labour market participation (the proportion of the population that wants to be employed) and unemployment (the proportion of labour market participants that are unemployed).

This study will add to the limited list of studies conducted to assess the costs of productivity losses of violence against girls and women [25].

In our study, indirect costs (i.e. those of productivity losses) remain high, estimated at $105,729 €$ for the victims and 2,926,543 $€$ for the perpetrators.

On the other hand, when the direct costs to the health care system are taken into consideration alongside the indirect costs to society, the total costs can reach billions [17]. Violence erodes women's health, consumes health care, and compromises the health and safety of children and communities.

The study by Yang $\mathrm{J}$ et al show that the indirect costs of sexual violence were estimated at $\$ 4.4$ billion [32] a figure much higher than what is presented in this paper, with the cost of lost productivity for the victims is estimated at 3331 $€$ and $1,868,499 €$ amongst the perpetrators. A study conducted in the United States, the costs of lost productivity linked to violence between intimate partners were estimated at $\$ 1.3$ trillion or $37 \%$ of the total cost [22]. In the study by Senior $M$ et al on the economic impact of violence perpetrated by people suffering from serious mental illnesses, these costs of lost productivity were estimated at $£ 348.0$ [1900-6288] million [26]. The very high costs of productivity losses among the perpetrators represent $63.8 \%$ of the total costs of lost productivity. Compared to the victims, the costs are higher for the perpetrators which can be in part explained by the long-term incarceration resulting from the committed offense. Perpetrators of rape may be incarcerated between 5 to 10 years. On the other hand, due to poorly maintained or missing medical certificates and court files, the duration of total incapacity for work is not fully considered while estimating the costs to the victims.

The valuation of lost productivity is influenced by biases in earning patterns, women earn less. Most perpetrators of violence and also men and therefore higher earners, which is another important explanation for why their costs are much higher.

Apart from the duration of total incapacity for work, the description of the clinical lesions remains a cause for concern; the characteristics of the lesions (shapes, dimensions, colours, contours) are not very precise.

It should be noted that in some cases, imprecise and inappropriate terms for medico-legal practices were used, and in other cases, these aspects have simply been omitted. This signals to the need to properly fill out medical certificates as these state medical facts which contribute to the establishment of evidence before a court [27]. As recommended by authors such as Grill et al, physicians must make greater efforts to provide quality medical certificates [8].
In the study by Nectoux $\mathrm{M}$ et al, the cost of incarcerations of people guilty of conjugal violence is estimated at $€ 98.838$ million [19]. Some authors argue that the costs of productivity losses are significant in relation to the overall cost of violence; productivity losses and human costs account for more than $50 \%$ of overall costs in 3 of the studies and in almost all studies this is the largest expense item [9, 23, 29]. Similarly, in the Peterson $C$ study, it is stated that $\$ 1.6$ trillion in lost labor productivity for victims and perpetrators accounted for $52 \%$ of overall costs [21].

According to Arnetz, the decline in productivity and quality of services has a negative impact on the image of a country and limits its attractiveness for potential investors [2].

As a result, prevention strategies will need to be strengthened to reduce morbidity and mortality, such as those related to violence against women and girls, in order to contribute to the country's development by boosting the economy. The new Agenda 2030 recognises that the prevention of violence against women remains an important strategy for the attainment of the sustainable development objective No. 5 [14].

Compared with men, women are twice as likely to be physically assaulted in the household, and three times more likely to be victims of touching or forced sexual intercourse both inside and outside of the household $[1,3,10]$.

It is therefore crucial to continue to make efforts to prevent this violence, and when it occurs, to protect and assist the victims, to compel the perpetrators of the violence to bear the consequences of their actions and to take the necessary measures so that the cycle does not continue through the next generations.

Aside from the costs of lost productivity, in a study by the Health Department of South Africa, the costs of dealing with victims of violence remain high. In fact, admission fees related to violence weighed heavily on patients [28]. According to Willem A, equality between men and women does not only depend on women's behaviour, but requires a profound cultural and organizational change by all actors, including men, employers and politicians [31].

Moreover, the judicial sanction of perpetrators of physical and / or sexual violence could contribute to the reduction of cases of violence in the population. This strategy must be coupled with others, in particular by raising awareness about the risks of drug use and the promotion of care services for people suffering from mental disorders secondary to the use of addictive substances [26].

\section{Conclusion}

This study estimated the costs of lost productivity in the workplace. These costs are enormous and have a negative impact on the country's economy due to the decline in productivity in the public and private sectors. The costs of lost productivity constitute a heavy economic burden borne by society. The average costs of productivity losses were higher among the perpetrators compared to the victims.

A study of costs, taking into account not only productivity losses, but also other indirect and direct cost items, 
conducted with the community (victims, aggressors and families) will highlight the economic burden of this violence against women and girls.

\section{Declaration of Links of Interest}

The authors declare that they have no links of interest.

\section{Acknowledgements}

We thank the Preventive Medicine and Health Service, the African Center of Excellence for Mother and Child Health and the World Bank Group for carrying out this work.

\section{References}

[1] Anderson JC, Stockman JK, Sabri B, Campbell DW, Campbell JC. Injury outcomes in african american and african Caribbean women: the role of intimate partner violence. J Emerg Nurs. 2015; 41 (1): 36-42.

[2] Arnetz JE, Arnetz BB. Violence towards health care staff and possible effects on the quality of patient care. Soc Sci Med, 2001; 52 (3): 417-27.

[3] Bah H, Abatty OC, Baw A, Soumah MT. Domestic violence in Conakry. J Med Leg Law Med, 2008; 51 (4-5): 221-225.

[4] Direction of Forecasting and Statistics. Employment, unemployment and conditions of activity in the agglomeration of Dakar. Report of phase 1 of the 1-2-3 survey of 2002. Dakar: DFS. 2004.

[5] Drummond MF, Sculpher MJ. Torrance GW. Methods for the Economic Evaluation of Health Care Programmes, Oxford University Press. 2005.

[6] Greenberg PE, Kessler R, Birnbaum HG, Leong SA, Lowe SW, Berglund PA, Corey-Lisle PK. The economic burden of depression in the United States: how did it change between 1990 and 2000? Journal of Clinical Psychiatry. 2003; 64: 1465-75.

[7] Greenberg PE, Leong SA, Birnbaum HG, Robinson RL. The economic burden of depression with painful symptoms. J Clin Psychiatry. 2003; 64 Suppl 7: 17-23.

[8] Grill S, Blanc A, Dedouit F, Rouge D, Telmon N. Evaluation of the quality of the drafting of descriptive certificates of the findings of Coups and Injuries volants within a medicojudicial unit. J Med Leg Droit Med, 2006; 49 (5): 166-172.

[9] Heiskanen M. The costs of violence in a municipality. A case study of violence against women and itse costs in the city of Hämeenlinna 2001, based on estimates provided by authority representatives. Sosiaali-ja terveysministeriö. 2002.

[10] Ho-Foster A, Laetsang D, Masisi M, Anderson M, Thoiwe D, Cockcroft A, Andersson N. Gender-specific patterns of multiple concurrent sexual partnerships: a national cross sectional survey in Botswana. AIDS Care, 2010; 22 (8): 1006-11.

[11] Huck A, Delbreil A, Gaudin A, Blanchard M, Chailloux C, Rougé-Maillart C. Determination of total incapacity for work during psychological disorders: criteria and methods. Journal of Legal Medicine, 2017; 8 (3): 105-115.
[12] International Labor Office. Decent Work Country Profile Senegal. Geneva: ILO; 2013; 49 p.

[13] Jacquemot P. Mineral resources, weapons and violence in the Kivus (DRC). Herodotus, 2009; 134 (3): 38-62.

[14] Kjaerulf F, Lee B, Cohen L, Donnelly P, Turner S, Davis R, Realini A, Moloney M.-K, Gordon R, Lee G, Gilligan J. The 2030 agenda for sustainable development: a golden opportunity for global violence prevention. International Journal of Public Health, 2016; 61, 8: 863-864.

[15] Leye, MMM, Faye A, Wone I, Diedhiou D, Diongue M, Niang K, Seck I, Ndiaye P, Tal Dia A. Etude des determinants de viols chez les mineurs dans la region de Kolda au Senegal. Sante Publique, 2014; 26, 131-138.

[16] Ministry of Labour, Social Dialogue, Professional Organisations and Relations with Institutions. Minister Decree No. 01418 dated 02 February 2015 approving the amendment of Article 6 of the Statutes of the Pension Provident Institution of Senegal. 2015.

[17] Mitchell C. The health impact of intimate partner violence. J Calif Dent Assoc, 2004; 32 (5): 396-8.

[18] National Agency of Statistics and Demography. National Survey of the Informal Sector in Senegal (ENSIS 2010). Dakar: NASD; 2013; 64 p.

[19] Nectoux M, Mugnier C, Baffert S, Albagly M, Thélot Bertrand. Economic evaluation of domestic violence in France. Public Health, 2010, 4 (22): 405-416.

[20] Niang CI, Diop N, Diop ML, Sow S, Gueye M A et al. Final report of the situational study on gender-based violence in the regions of Dakar, Diourbel, Fatick, Kaffrine, Kaolack, Louga, St. Louis, Thies. UNFEMMES-Senegal. 2012; 85 p.

[21] Peterson C, DeGue S, Florence C, Lokey CN. Lifetime Economic Burden of Rape Among U.S. Adults. Am J Prev Med, 2017; 52 (6): 691-701.

[22] Peterson C, Kearns MC, McIntosh WL, Estefan LF, Nicolaidis C, McCollister KE, Gordon A, Florence C. Lifetime Economic Burden of Intimate Partner Violence Among U.S. Adults. Am J Prev Med; 2018; 55 (4): 433-444.

[23] Pulkkinen P. The price of violence. The costs of men's violence against women in Finland. Statistics finland. Workingpaper 30. 2004.

[24] Selke B, Durand I, Marissal JP, Chevalier D, Lebrun T. Cost of colorectal cancer in France in 1999. Gastroenterol Clin Biol, 2003; 27 (1): 22-7.

[25] Semahegn A, Mengistie B. Domestic violence against women and associated factors in Ethiopia; systematic review. Reprod Health, 2015 12: 78.

[26] Senior M, Fazel S, Tsiachristas A. The economic impact of violence perpetration in severe mental illness: a retrospective, prevalence-based analysis in England and Wales. Lancet Public Health. 2020 Feb; 5 (2): e99-e106.

[27] Soumah MM, Ngwa HE, Ndiaye M, Sow ML. Quality of certificates of voluntary assault on adults in Dakar and Diourbel. Pan African Médical Journal, 2011; 12: 59.

[28] Steyn TP, Gebremariam FA. Cost analysis of violence-related medical imaging in a Free State tertiary trauma unit. SA J Radiol. 2019 Jan 8; 23 (1): 1664. 
[29] Tournyol du Clos L, Le Jeannic T. Violence against women. Paris: The national institute of statistics and economic studies, 2008, n¹180: 4 p.

[30] Waters H, Hyder A, Rajkotia Y, Basu S, Rehwinkel JA, Butchart A. The economic dimensions of interpersonal violence. Department of Injuries and Violence Prevention. Geneva: World Health Organization. 2004.
[31] Willem A, Olivier T. Gender equality as a factor of economic growth: what can policies? Geoeconomics, 2016; no 2, 141163.

[32] Yang J, Miller TR, Zhang N, LeHew B, Peek-Asa C. Incidence and cost of sexual violence in Iowa. Am J Prev Med, 2014; 47 (2): 198-202. 